\title{
Review Paper: International Agreements on Disaster Risk Management Based on World Conferences, Successful or Not: A Review Study
}

\author{
Vahid Delshad $^{1}$ (D), Negar Pourvakhshoori ${ }^{2}$ (D), Elham Rajabi ${ }^{1}$, Jafar Bazyar ${ }^{1,3}$, Shokofeh Ahmadi ${ }^{1}$, (D), Hamid Reza Khankeh ${ }^{1,4^{*}}$ (D) \\ 1. Health in Emergency and Disaster Research Center, University of Social Welfare and Rehabilitation Sciences, Tehran, Iran \\ 2. Department of Nursing, School of Nursing and Midwifery, Guilan University of Medical Sciences, Rasht, Iran. \\ 3. Department of Nursing, Faculty of Nursing and Midwifery, Ilam University of Medical Sciences, Ilam, Iran. \\ 4. Department of Clinical Science and Education, Karolinska Institute, Stockholm, Sweden.
}

\begin{tabular}{|c|c|}
\hline $\begin{array}{l}\text { Use your device to scan } \\
\text { and read the article online }\end{array}$ & Cftation: Delshad V, Pourvakhshoori N, Rajabi E, Bazyar J, Khankeh HR. International Agreements on Disaster Risk Man- \\
\hline 口ifipg & $\begin{array}{l}\text { agement Based on World Conferences, Successful or Not: A Review Study. Health in Emergencies and Disasters Quarterly. 2020; } \\
6(1): 1-8 . \mathrm{http}: / / \text { dx.doi.org/10.32598/hdq.6.1.38.4 }\end{array}$ \\
\hline 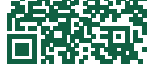 & dol': http://dx.doi.org/10.32598/hdq.6.1.38.4 \\
\hline
\end{tabular}

\section{(c) (1) (5)}

Article info:

Received: 10 Aug 2020

Accepted: 05 Sep 2020

Available Online: 01 Oct 2020

\section{Keywords:}

International conference, Sendai, Hyogo, Yokohama,

Risk management,

Emergencies, Disasters

\section{ABSTRACT}

Background: At the end of the $19^{\text {th }}$ century, international communities have realized the necessity of global planning and cooperation. Accordingly, worldwide meetings have been organized for several years. This study aims to assess the achievement of predetermined objectives by international conferences in the field of risk management.

Materials and Methods: The search for articles and documents was done using several keywords of "international meetings", "Sendai", "Hyogo", and "Yokohama" in Scopus, Web of Science, PubMed, Cochrane Library, Science Direct, Google Scholar databases. Also, the risk management domain websites such as FEMA, UNISDR, and EM-Date were searched.

Results: Three Disaster World Conferences have been organized, hosted by Japan: Yokohama 1994, Kobe 2005, and Sendai 2015. They proposed strategies and prioritized actions for managing disaster risk, reducing the risk of disasters, and coping with disasters. In the second and third conferences, as requested by the United Nations (UN General Assembly), the UN Office for Disaster Risk Reduction (UNISDR) helped as the coordinating body.

Conclusion: Reducing the risks of disasters is a global issue, which needs international cooperation. Therefore, all countries should take steps to achieve disaster risk reduction goals. Since declaraions, documents, resolutions, and conferences do not impose an obligation on countries in this regard, the success rate of the programs is dependent on voluntary international cooperation. Moreover, while we do not expect that outcomes of these international agreements related to disaster risk reduction be achieved at the scheduled time plan, strengthening the international cooperation of the countries to facilitate the improvement of actions and programs would be effective.

\section{* Corresponding Author:




\section{Introduction}

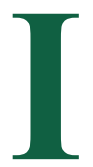

nternational statistics indicate that emergencies, disasters, and their affected population are increasing in the world. Today, societies are increasingly exposed to disasters for divergent reasons such as climate change, population growth, urbanization, inequality, and inappropriate risk management policies $[1,2]$.

In addition to the devastating impact on human health and welfare, emergencies and disasters can cause widespread economic and environmental losses and threaten sustainable development in many countries, especially in developing countries [3]. Previous experiences have shown that by reducing vulnerability and increasing the response capacity, as the building blocks of disaster risk management, disasters can be significantly reduced [4]. Since the presence of these effects in one area can lead to a reduction or increased risk of disasters in other areas, communities can share their experiences in the field of disaster risk management. This result confirms the fact that today the problem of disaster risk and its management has become a primary global concern and, besides acting at the local and national levels, taking practical international actions are necessary, too [5]. The increasing number of events and their complexities necessitate reduction of disaster risk, strengthening the humanitarian nature of international assistance, and development of international cooperation and agreement of different countries [6].

Sharing international experiences can prevent potential trial and error in disaster management and have a significant role in reducing the risk of disasters and promoting the safety culture of communities. To develop international cooperation in this sensitive area, previous international meetings and documents must be thoroughly scrutinized. By exploring the strengths and weaknesses, appropriate strategies can be recommended to enhance their effectiveness.

Since no previous study on reviewing international agreements in the area of disaster risk management of emergencies and disasters was found, the present study has only examined and evaluated the international conferences on the aforementioned field.

\section{Materials and Methods}

This research is a review study that investigates the strength and weaknesses of international meetings in the field of disaster risk management. The search for the resources was done using several keywords, including "risk management", "conference", "congress", "meeting", "international", "documents", "Sendai", "Hyogo", and "Yokohama" in Scopus, Web of Science, PubMed, Cochrane Library, Science Direct, Google Scholar, Irandoc, Magiran Iranmedex, and SID databases and also in websites and search engines dedicated to risk management, including FEMA, UNISDR, EM-DAT in English and Persian.

\section{Results}

Early efforts to establish an international natural disaster risk management program in the United Nations dates back to the $1980 \mathrm{~s}$, which resulted in naming the second week of October as the International Disaster Risk Reduction Week in 1989. Also, on December 22, 1990, a discourse was established for countries to help to save people and mitigate the effects of disasters. Subsequently, assuming that a broad global commitment should be created in this way, in December 1991, the General Assembly resolution (No. 46/182/19) to establish an integrated approach to crisis management was issued. It was considered the beginning of a global trend in the prevention phase. Considering that countries cannot achieve sustainable economic growth without reducing the effects of natural disasters and environmental degradation, a conference on development and the environment was held in Rio de Janeiro from 3 to June 14, 1992, by the United Nations. Four of the 27 principles of the Rio Declaration's statement emphasize the following issues [7].

Principle 1 emphasizes the desirability of a human being for a healthy and creative life in harmony with nature. The fourth principle refers to the need for environmental protection. The sixth principle refers to the priority of the needs of low- and middle-income countries, and the 18th principle refers to the need to share information and experiences between countries in the context of natural disaster risks, as well as helping countries involved with emergencies and disasters [8].

As a result, considering the increase in the global impacts caused by natural disasters, the first international disaster risk reduction conference was held in Yokohama, Japan, from 23 to May 27, 1994, upon the request of the General Assembly (resolution No. 48/188 of December 21, 1993). The 1990s was announced as the International Decade for Natural Disaster Reduction [9] to reduce the impact of natural disasters and even human casualties.

The Yokohama Summit's strategy was to create a safe and secure world to prevent, prepare, and mitigate the effects of natural disasters and build its roadmap. 
The strategy included three main sections:

1. Describing the basic principles of reducing the effects of natural disasters, on which countries must rely;

2. Developing a practical action plan which is accepted by all countries;

3. Issuing instructions related to the follow-up of the action plan.

Accordingly, the most critical points and basic principles include:

Reviewing the achievements of the first decade, increasing the capacity for preventing and reducing natural disasters, providing necessary facilities, including early warning systems and effective communication, preventative measures involving all international, national, regional, and local capacities, reducing vulnerability through appropriate training, providing new technologies, protecting the environment as an essential component of sustainable development, and finally emphasizing the fact that the sovereignty of the countries is responsible for the protection of its people. So the international community must have a strong political determination to properly and efficiently use the available resources (financial, scientific, and technological) to reduce natural disasters.

Despite these efforts, because of no specific mechanism to follow up and enforce the laws, there was no noticeable progress in achieving the above-mentioned goals from the Yokohama Strategy for a safer world. For this reason, the UN General Assembly assigned the secretariat of the International Strategy for Disaster Reduction as the coordinating body in the 219/54 RES/A resolution on February 3, 2000, to evaluate its achievements, and also review and probably extend this strategy [10].

The International Strategy for Disaster Reduction (ISDR) is the most critical part of the United Nations to reduce the mortality and financial, social, economic, and environmental losses caused by natural disasters and their problematic technological and ecological consequences. It is also involved with risk-related activities, increasing knowledge and awareness of people for sustainable development, and creating more resilient societies. The head office of the global database (ISDR) is based in Geneva, which provides information about reducing incidents, raising public awareness, publishing articles, books, and reports on disaster risk management. [11].
The lack of significant practical progress, since the Yokohama Conference, as well as the specific mechanism for the follow-up and implementation of the document approvals, caused the organization of the second World Conference on disaster risk in the city of Kobe, the Hyogo province of Japan from January 18 to 22, 2005. Therefore, a framework for action was established for the years 2005 to 2015 , with the slogan of creating reciprocity and resilience of nations and communities. Ultimately, with the strong agreement and recommendations of more than 160 UN member states, public institutions, and NGOs, the result of this conference was issuing a document called Hyogo Framework for Action (HFA) [12].

The conference provided an equal opportunity to support and encourage a systematic and strategic approach to reduce vulnerability and hazards in disasters. This gathering underscored the needs and the ways to create reversibility and resilience of nations and communities in the face of crises [12]

The more effective integration of risk considerations, particular emphasis on preventing and mitigating the effects of disasters, preparedness, and reducing vulnerability in sustainable development policies, developing and strengthening institutions, mechanisms, and capacities at all levels, especially at the local level, systematic integration of risk reduction approaches in the design and implementation of preparedness programs, coping and rehabilitation programs aimed at rebuilding communities were the main strategic goals of the Hyogo Action Plan.

Based on the results of the revision of the Yokohama Strategy and according to the discussions about strategic goals and expected outcomes, the Hyogo conference approved the following five priorities:

1. Guaranteeing disaster risk reduction as a national and local priority along with a strong organizational base for implementation;

2. Identifying, assessing, and monitoring the disaster risk and upgrading the early warning;

3. Utilizing knowledge, innovation, and education for the creation of safety and reversibility at all levels;

\section{Reducing the underlying and latent risk factors;}

5. Strengthening preparedness against disasters to provide an effective response at all levels; establishing an effective and appropriate relationship between processes for creating resilience and fulfilling the global goal of eradicating poverty. 
After the conference, it was decided to establish a secretariat in each country to achieve the goal, follow up the congressional approvals, and avoid problems observed in the Yokohama conference. It was also agreed that the Hyogo Framework for Action (HFA) should be appropriately reviewed at further annual conferences. UNISDR was also requested to report periodical revisions and the progress made to achieve its goals and priorities. To implement this request, the secretariat of the International Strategy for Disaster Reduction conducted a mid-term HFA revision in 2010-2011 through a participatory approach with the participation of partner institutions. Also, the 66/199 resolution of the United Nations General Assembly requested UNISDR to establish a framework for reducing disasters after 2015 [13]. The draft of this proposal should have been finalized at the end of 2014 and agreed upon in the World Conference on Disaster Reduction in 2015.

At the conference held on July 14 and 15, the Geneva Initiative Committee was given a mission to examine the issues related to the reduction of disaster risks and to hold meetings in September and October 2014.

The United Nations General Assembly then decided, in the $\mathrm{A} / \mathrm{RES} / 68 / 211$ resolution, in 2014 , to review the outcome of the conferences at a precise and concise summit and issue an applicable and operational document at the end of this summit. All these points were considered in the form of the following items:

1. The International Decade for Natural Disaster Reduction (IDNDR) in 1989;

2. Yokohama's Strategy for a Safer World 1994;

3. International Disaster Reduction Strategy 1999;

4. Hyogo Framework for Action 2005;

5. Conferences held in this area as well as resolutions of the United Nations General Assembly:

- (A/CONF.224/PC (I)/5);

- (A/CONF.224/PC (I)/6);

- (A/CONF.224/PC (I)/7, 8, 9, 11, 12);

6. The proposal of the United Nations working groups on the achievement of the Millennium Development Goals and the recommendations of the UNISDR special committee [14].
HFA2 also determined the continuation of the International Decade for Natural Disaster Reduction and has been assigned as the Hyogo Framework for Action 2005-2015 to strengthen the Yokohama Action Plan and the United Nations International Disaster Reduction Strategy (1999). The issues addressed in HFA2 include:

- Establishing appropriate investment in high-risk areas and strengthening them after disasters;

- Using country leaders in disaster management;

- Applying disaster risk reduction policies and appropriate planning compatible with the political and administrative structures in the countries;

- Providing programs, participatory institutions, and the participation of all stakeholders;

- Increasing leadership capacity to reduce the risk of natural disasters, especially at the local level;

- Focusing on poverty reduction, which is a significant factor in reducing disaster risk and reversibility of societies;

- Informing and raising awareness about the risks of investing without insurance and strengthening insurance;

- Paying attention to developing countries, small islands, landlocked, less developed countries, Africa and sharing tools, information, capacities, and technical cooperation with these countries [15].

Following the two meetings of Yokohama and Hyogo, the third international document was approved by the United Nations World Conference held in Sendai on March 18, 2015. The drafting of this framework began after consultation with the stakeholders in March 2012. With the negotiations made between different governments from July 2014 to March 2015, upon the request of the UN General Assembly and the coordination of the Office of the United Nations, the Sendai document was subsequently issued. There are seven goals assigned for countries in this document to be achieved from 2015 to 2030. These goals refer to reducing mortality, damage, and suffering caused by natural disasters. The seven global objectives of the document are listed below:

1. A substantial reduction in global mortality rates by 2030 , to reduce the average annual death rate per 100000 population from 2015 to 2030 compared with from 2005 to 2015 ; 
2. A substantial reduction of the population affected by global disasters by 2030, to reduce the average annual rate per 100000 population from 2015 to 2030 compared with from 2005 to 2015;

3. A significant reduction in the direct economic losses caused by disasters in the world by 2030 at the global level of gross national product;

4. A significant reduction in the damage to critical infrastructure and the disruption of the essential services functioning by 2030 (including health and training facilities) through various means, encompassing promotion of resilience;

5. A substantial increase in the number of countries that have national and local strategies for reducing disaster risks by 2030 ;

6 . The promotion of international cooperation with developing countries by 2030 , through adequate and sustainable support to help complete the national measures to implement this framework;

7. Increase the provision and availability of early multihazard warning systems and disaster risk information and evaluations by 2030 through adequate and sustained support for completing national measures to implement this framework.

The six priorities of the Sendai document include understanding the disaster risk, strengthening disaster risk management, investing in disaster risk reduction for resilience enhancement, promoting disaster preparedness for effective response, improvement of rehabilitation and reconstruction, stakeholder roles, international cooperation, and global partnership [16].

The Sendai framework is based on elements that guarantee the continuity of the work through states and other stakeholders and ensure the Hyogo Framework for Action while introducing several innovations that have been put forward during the negotiations.

\section{Discussion}

This study aimed to scrutinize the achievements of international meetings in the field of disaster risk management. The results of the study indicate that international communities have decided to convene meetings to coordinate and plan for disaster risk management since the late 19th century. Three international conferences have been held in 1994, 2005, and 2015, and three international strategic documents of the Yokohama Safety Strategy, the Hyogo and Sendai documents were prepared, for disaster risk reduction, in the United Nations humanitarian system.

The global conferences, joint statements, and declarations on the natural disasters began from Yokohama's strategy for a more secure world in 1994 and were completed in the framework of the Hyogo Plan for Action (HFA1) in 2005 and continued in the HFA2 since 2015 onwards.

Yokohama's strategy emphasizes local understanding as a vital component of the planning and implementation of DRR. This strategy generally calls for strengthening DRR efforts by integrating traditional specialists and increasing the self-confidence of societies through the identification and transfer of traditional knowledge, in line with local values [10]. The document states: "Prevention, mitigation, and preparedness in disasters are better and more effective than responding to disasters in achieving the decade's goals." Furthermore, it was emphasized that the response to the disaster alone is not enough since it only has temporary results and brings about a very high cost. Since then, disaster risk reduction has become a significant contributor to the international development against natural disasters [17].

HFA has played an essential role in preparing countries, early warning systems, policies, and so forth, and declared the necessity of maintaining continuity with a more robust framework from 2015. It has also emphasized that risk management should enhance the economic and social reversibility of countries and reduce the vulnerability of individuals and property. Although the implementation of the HFA1 created gaps between the priorities, especially in the fourth priority, and in recognition of the stakeholders, HFA2 was considering an integrated framework for reducing disaster risk by updating orders, goals, strategies, and preferences that consider all levels [17].

According to the National Research Council (Washington DC, USA), disaster research, which historically focuses on emergency response and recovery, would be incomplete without simultaneously studying social and natural disasters risks (including information on the vulnerability, global politics, and information at the National Academy of Sciences, Engineering, and Medicine), which was not much addressed in the Yokohama and Hyogo's documents [7].

The Sendai framework (2030-2015) is the most critical UN disaster risk reduction strategy for the next 15 years. Its initial and expert reviews have been done by various 
countries between 2012 and 2015 and were supported by the United Nations. It provides countries with the following opportunities:

1. Approving a concise, focused, operational, and prospective framework for disaster risk reduction measures in the years after 2015;

2. Completing, evaluating, and reviewing the implementation of the Hyogo Framework for Action 20052015 (Resilience of Nations and Communities against Disasters);

3. Taking into account the experiences gained from national and international disaster risk reduction plans, institutions, and recommendations, and mentioning the regional agreements related to the implementation of the Hyogo framework;

4. Identifying commitment-based cooperation methods for the implementation of the post-2015 framework to reduce disaster risk;

5. Determining the procedures for periodic review of the implementation of the disaster risk reduction framework in the years after 2015 .

Despite the unique opportunity provided by the Sendai framework to the nations, this document and the international agreement were not much successful. One of the most influential factors behind this failure, as pointed by Washington DC, is that it is impossible to coerce countries or establish international forces or organizations for natural disaster risks to support this agreement legally. Moreover, it is not possible to persuade countries to reconstruct residential homes or to take preventive policies. However, it is possible to recommend or encourage them to move through this path [7].

On the one hand, there has been a series of incidents and events in the world after the conference, and the objectives of the Sendai document have not materialized. One of the 7 crucial goals in the Sendai framework for disaster risk is the significant reduction in global mortality by 2030 . This goal has not been achieved to date, and even the rate has not been significantly reduced [18].

It should be noted that today, with the increasing number of natural emergencies and disasters in the world, the reduction of risk as a global priority requires a joint effort of policymakers, managers, professionals, and all stakeholders in this area. In this regard, the skillful use of global knowledge and experiences, including the strict implementation of the strategies mentioned in the Sendai framework, could be a useful and indispensable step in reducing the scale of natural disasters in the world in general. Through communicating with international organizations and formulating long-term and rational strategies, the experts, policymakers, and planners of the country can ensure the country's access to sustainable development by managing the risk of emergencies and disasters, which is the real message of the Sendai framework for sustainable development.

In Sendai's statement, most countries have reported their actions and pointed to their weaknesses. So, it seems that they have failed to achieve their objectives fully. International mechanisms in the field of risk management can help countries to improve risk management and sustainable development capacities by recommending preventive strategies, cooperation, and participatory development.

Workshops, conferences, summits, and joint statements can facilitate the process of advocacy and commitment of involved countries. Though these meetings might be transient, they can efficiently influence and improve. And it seems safe to claim although these conferences are novel, they can efficiently grow [7].

According to United Nations statistics, only $0.4 \%$ of the $\$ 135.2$ billion global relief budget, namely $\$ 540$ million, is spent reducing the risk of natural disasters. While five times the current budget should be considered to reduce the impact of natural disasters. However, at the UN 2015 summit in Istanbul, it was decided to increase the budget from $0.5 \%$ to $1 \%$. Many experts and practitioners consider the most significant changes to this document to emphasize disaster risk management rather than disaster management and the determination of global dedicated goals. Accordingly, the programs' vagueness, lack of any obligation for high-rank authorities for participation, no support of the legislative system of the countries concerning documents, absence of monitoring systems, the inappropriateness of the development programs of the countries, and so forth, should be all taken into consideration. Conducting further qualitative studies, which examine the experiences of countries that have failed to achieve their goals, seems essential.

In general, it appears that all international meetings and their proposed statements and frameworks emphasize the participation and increase of national and international commitment, addressing all sorts of risk, which means that we can manage and control the risk of emergencies and disasters with global coordination and integration. 
As a review study, the current paper reviewed the summary of international measures to meet sustainable development goals and the criticisms addressed at these meetings on reducing disaster risks. Nevertheless, the need for conducting a systematic review to examine all the angles of this subject is felt. Many articles were not open-access, and the number of papers in this area was limited.

\section{Conclusion}

Reducing the risks of disasters is a subject that requires international cooperation. That is, all countries should take steps to achieve these goals. Since declarations, documents, strategies, and conferences do not impose an obligation on the countries in this regard, the success rate of the programs is dependent on voluntary international cooperation. While many sustainable development goals have not been achieved in many countries, it is anticipated that disaster risk reduction programs would not be reached, at least in certain countries at the appointed time. Therefore strengthening international relations of the countries to facilitate the advancement of actions and programs can be effective. Given the profound impact of emergencies and disasters on the community, especially the less developed countries and vulnerable groups, the international forums should attempt to remove their political barriers and constraints, including international sanctions, and pave the ground for quick and appropriate responses, which can accelerate the global participation of these countries. Furthermore, the approval of binding United Nations resolutions to assist and facilitate the participation of developed countries in the advancement of infrastructure and sustainable development goals in less developed countries should also be prioritized.

Ultimately, there are several issues such as governance structure, factors affecting risk reduction, poverty, and national policies, which should be further assessed. The contextual, cultural, and social diversities and the need for the participation of all people and all national and international stakeholders in disaster risk management should be considered in the development of international documents.

\section{Ethical Considerations}

\section{Compliance with ethical guidelines}

There were no ethical considerations to be considered in this research.

\section{Funding}

This research did not receive any grant from funding agencies in the public, commercial, or non-profit sectors.

\section{Authors' contributions}

All authors equally contributed to preparing this article.

\section{Conflict of interest}

The authors declared no conflict of interest.

[1] Chikeya F, Njihia I. City resilience: Implementing the sendai framework at the local level. Paper presented at: Water \& Climate Congress Birchwood Hotel \& oR Tambo Conference Centre, Ekurhuleni Metropolitan Municipality. 22-24 March 2017; Bloemfontein: South Africa. https://www.preventionweb.net/ files/52422_LOCS4AFRICANote.pd

[2] Weichselgartner J, Sendzimir J. Resolving the paradox. Mountain Research and Development. 2004; 24(1):4-9. [DOI:10.1659/02764741(2004)024 [0004:RTP]2.0.CO;2]

[3] EM-DAT. The international disaster database [Internet]. 2020 [Updated 2020 January 10]. Available from: https:/ / www.emdat.be/

[4] Basher R. Global early warning systems for natural hazards: Systematic and people-centred. Philosophical Transactions of the Royal Society A. 2006; 364(1845):2167-82. [DOI:10.1098/rsta.2006.1819] [PMID]

[5] Carrão H, Naumann G, Barbosa P. Mapping global patterns of drought risk: An empirical framework based on sub-national estimates of hazard, exposure and vulnerability. Global Environmental Change. 2016; 39:108-24. [DOI:10.1016/j.gloenvcha.2016.04.012]

[6] Pereira T, Shackleton S, Donkor FK. Integrating Climate Change Adaptation (CCA) and Disaster Risk Reduction (DRR) for greater local level resilience: Lessons from a multi-stakeholder think-tank. Policy Brief. 2017; 16. https://www.researchgate.net/profile/Taryn_Pereira2/publication/329118387_

[7] Administration Standard of Qom. Naghshe Qom 97 [Internet]. 2018 [Updated 2019 September 10]. Available from: http://qom.isiri.gov. ir/portal/file/?600482/naghshe-qom-97.pdf

[8] Hens L. The rio declaration on environment and development sustainable development review [Internet]. 2005 [Updated 2020]. Available from: http://www.eolss.net/sample-chapters/c16/E1-48-43.pdf

[9] Katayama T. International Decade for Natural Disaster Reduction: Are we chasing a dream? Paper presented at: In Proceedings of IECON' $93-19^{\text {th }}$ Annual Conference of IEEE Industrial Electronics. 15 19November 1993; USA: Maui. https:/ /ieeexplore.ieee.org/abstract/ document/339116

[10] United Nations Office for Disaster Risk Reduction.Yokohama strategy and plan of action for a safer world: Guidelines for natural disaster prevention, preparedness and mitigation. Paper presented at: World Conference on Natural Disaster Reduction. 23-27 May 1994; Japan: Yokohama. https://www.undrr.org/ publication/yokohama-strategy-and-plan-action-safer-worldguidelines-natural-disaster-prevention 
[11] United Nations (UN). Resolution adopted by the general assembly [Internet]. 2000 [Updated 2000 February 3]. Available from: https://www.unisdr.org/files/resolutions/ N0027175.pdf

[12] United Nations Office for Disaster Risk Reduction. Hyogo Framework for Action 2005-2015: Building the resilience of nations and communities to disasters. Paper presented at: World Conference on Disaster Reduction. 18-22 January 2005; Japan: Kobe. https://www.undrr.org/publication/ hyogo-framework-action-2005-2015-building-resilience-nations-and-communities-disasters

[13] United Nations: General assembly. Resolution adopted by the General Assembly [Internet]. 2012 [Updated 2012 February 28]. Available from: https://www.preventionweb.net/ files/resolutions/N1147076.pdf

[14] United Nations: General Assembly. Resolution adopted by the General Assembly on 20 December 2013. [Internet]. 2014 [Updated 2014 January 29]. Available from: https://www. unisdr.org/files/resolutions/ARES68211E.pdf

[15] Shia News Association. Meeting of Environmental Crises and Natural Disasters; consequences and solutions were held [Internet]. 2017 [Updated 2017 October 11]. Available from: https://fa.shafaqna.com/news/462880

[16] United Nations Office for Disaster Risk Reduction. Sendai framework for disaster risk reduction 2015-2030. Paper presented at: Third UN World Conference on Disaster Risk Reduction. 18 March 2015; Japan: Sendai. https:/ /www.undrr.org/publication/sendai-framework-disaster-risk-reduction-2015-2030

[17] Keim M. Managing disaster-related health risk: A process for prevention. Prehospital and Disaster Medicine. 2018; 33:326-4. https://www.researchgate.net/profile/Mark Keim/publication/325511759

[18] Centre for Research on the Epidemiology of Disasters - CRED. 2018 review of disaster events [Internet]. 2019 [Updated 2020]. Available from: https://www.cred.be/2018review-disaster-events 